\title{
Response: Naoko Saito, Finding as Founding: Rejoinder to René Arcilla's Review, Naoko Saito, Associate Professor of Education at Kyoto University, Japan. Kyoto University, Yoshidahonmachi, Sakyo-ku, Kyoto 606-8501
}

\author{
Naoko Saito ${ }^{1}$
}

Accepted: 27 August 2020 / Published online: 28 September 2020

(c) Springer Nature B.V. 2020

Finding as Founding: Rejoinder to René Arcilla’s Review

Naoko Saito

I appreciate René Arcilla's careful reading of my paper. In his every word, he hits the right spot in elucidating the crucial points I wanted to make in my writing. I am honored to have such an insightful and sincere reader as Arcilla as my respondent and as a conversational partner. In particular, his foregrounding of the nature of my book as a response to diverse forms of crisis is pertinent to our times. It makes me rethink the role of American philosophy as a philosophy in response to crisis and about how the idea of translation bears on this-especially when he says that I prophesy the shadow of the current Covid-19 pandemic and its effect upon our whole ways of living. My rejoinder to Arcilla is triggered by my desire to respond to his telling points of criticism and to the crisis of our times, and I hope this to be more than a merely academic exchange.

The first point I would like to respond to is the goal, if any, of translation. What purpose does it serve? Why do we need translation, especially at times of crisis? Arcilla seems to think it is needed for better understanding and knowledge of the other. As he says:

[W]e may form or educate each other to make ourselves at least partially understandable. In this fashion, we find words with others, and others with words, that can serve as a temporary, but for the moment sufficient, support for cooperative living, living with doubt (Arcilla 2020).

In one sense, this is indubitable: we are engaged in translation for mutual understanding, so that we might live better together. In the current crisis of the pandemic, when social distancing keeps people apart physically, the need of such mutual understanding is increasing. In another sense, however, the idea of translation I discuss in the book, especially in connection with Cavell's idea of skepticism, directs us to a slightly different way than this Deweyan discourse of mutual understanding. For Cavell, as I discuss in Chapter 6, living

Naoko Saito

saito.naoko.6v@kyoto-u.ac.jp

1 Graduate School of Education, Kyoto University, Yoshidahonmachi, Sakyo-ku, Kyoto 606-8501, Japan 
with doubt is not a matter of "partial understanding" and, implicitly, "partial misunderstanding," both of which seem to be trapped in the mode of knowing and recognizing the other. For Cavell, the response to skepticism is not a matter of knowledge, but acknowledgment-learning how to close your eyes in correct blindness (Wittgenstein 1953, Philosophical Investigation Part II, Section XI, p. 224; Cavell 1979, The Claim of Reason: Wittgenstein, Skepticism, Morality and Tragedy. Oxford: Oxford University Press). It requires commitment of yourself to the other and receptivity to the other, and this is accompanied by the rigor of language. In this sense, the response to skepticism is not a matter of clearing away doubt. Rather it has to do with something inherent in the human condition: skepticism will return and we need to live with it. Cavell's view is more tentative, and he conceives of ordinary language as more fragile than perhaps Arcilla wishes it to be. In times when we are compelled to live in virtual reality in some degree, learning to have correct blindness becomes a pressing need: we need to sensitize ourselves to the possibility of failures of understanding, of our intelligibility, and to the possibility of delusion and selfdeception made more acute by virtual reality.

Then the emphasis in the idea of translation is to be not so much on the making of our experiences intelligible as on a kind of risk-taking, with language opening itself to diverse possibilities, beyond human control. (This is an aspect of Cavell's philosophy that is not far from Derrida's views.) In Cavell's ordinary language philosophy, translation does not take place only between different language systems. Rather it is internal to the nature of language itself - as in, for example, the transience and groundlessness of our words, the obscurity of human expression, and the essential rift in the experience of the untranslatable. We need to stand on the always shifting, contextually defined border between the inner and the outer. This is the very experience of translation. What Cavell, along with Thoreau, calls "conviction" (Cavell 1992, p. 34) is not a matter of confidence or assurance, with a sense of security: conviction is more like a determination and resolution to take one's stand, to profess one's words in the midst of uncertainties: what is at stake here is not rightness or correctness. The future is vague- "I desire to speak somewhere without bounds; like a man in a waking moment, to men in their waking moments" (Thoreau 1992, p. 216). Arcilla's quest for understanding and knowing seems to mute this risk-taking dimension of Cavell's ordinary language philosophy and the idea of translation. (And this risk-taking dimension is what I discuss in Chapter 3 in reference to the Emersonian way of transcending the tragic.)

Thus the "goal" of translation, if there is one, is not to reach some common ground of understanding, but to be aware of the difficulty of or a limit in understanding, of an unbridgeable gap that lies between human beings. We might even say that it is goalless. And this I think is the lesson we should learn in times of the pandemic crisis when prejudice, the pretense of understanding behind self-justification, becomes a social crisis of consequence.

The second point I want to respond to is what I call "antifoundationalism." Arcilla is concerned about this on the grounds that it might create an academic, dialectical mode of confrontation, which he thinks goes against the spirit of bidirectional translation. There are two issues to be disentangled here. The first is the very concept of antifoundationalism and its relation to translation: and the second is a more meta-level issue involving the mode of academic dialogue. Let me address these one by one. Arcilla says: "these anxieties largely come down to the realization that there is no sure foundation for our social life. This is what [Saito] means when she calls this philosophical conception of translation, 'antifoundationalist' (Arcilla 2020)." This phrasing makes me realize that my use of the term "antifoundationalism" has been wrongly taken to be the opposite of foundationalism - that 
is, as a state of "no sure ground." This falls into the dichotomy of absolutism and relativism. My whole attempt in the book with the idea of American philosophy in translation is to find a third way beyond this dichotomy, and the "antifoundationalism" I present is this very alternative mode of thinking. What I mean by "antifoundationalism" is not a flat negation of the foundation. Its focus is more on its process-oriented movement, philosophy on the way, what Cavell calls "onward thinking" (Cavell 1992, p. 135) or what he calls after Emerson "finding as founding" (Cavell 1989, p. 77) (see Chapter 3)-which is a matter of revising criteria and finding foundations, recurrently and continually. As Cavell says about Emerson:

Emerson may be understood to be saying that the world of the temperament open to surprise is different from that of the one closed; the mood of the one prepared to be useful to the world is different from that of the one prepared to adapt to it; the world of the dreaming from that of the dreamless; that of the one willing for succession from that of the one wedded to fixation; and so on. The existence of one of these worlds of life depends on our finding ourselves there. They have no foundation otherwise. No grown-up philosophy can secure the permanence of any, but grown-ups can destroy or deny any. Their chagrin is aversion of our joy. (ibid., pp. 96-97).

A finding in every step is the description of a series, perhaps in the form of a proof, or a sentence. (ibid., pp. 114-115).

Such antifoundationalism, finding as founding, is the very nature of translation: there is no endpoint in the endeavor of translation. This does not mean, however, there are no grounds or no criteria: "There is a solid bottom everywhere," as Cavell says, following Thoreau (Cavell 1992, p. 76). The antifoundationalist thinking I envision requires engagement in the revising of criteria.

I think this misunderstanding leads to the second point of criticism involving antifoundationalism-Arcilla's criticism that this goes against the spirit of bidirectional translation. This is a very Cavellian question with regard to the style of argument in one's writingwhether I as a writer fall into the oppositional manner of combating foundationalism by taking a stand for antifoundationalism. I accept Arcilla's criticism that my frequent use of the term "anti-" creates the impression that what I present in this book is a negation of foundation. But what I want to emphasize all through the book is, as I mention above, the Emersonian idea of finding as founding. With such a third possibility, beyond the dichotomy between foundation and lack of foundation, I hope that the "antifoundationalist" mode of the discussion does not contradict bidirectional translation.

The third and the final point is the idea of America, or of the Americanness of the idea, I explore in the book. Arcilla asks: "Could not the book's title be just as well, Japanese Philosophy in Translation?" And he continues: "Indeed, would anything be lost if it were simply, Philosophy in Translation?" (Arcilla 2020). Of course I am not generalizing about Americans or about philosophy in America. I am talking about Emerson, Thoreau and Cavell (and Dewey, and to some extent aspects of pragmatism). My title needs to word "American" as the book tries to celebrate critically some of the best assets of American culture. Americanness here is not confined to the country that is America, the United States, but in itself entails openness, the crossing of boundaries beyond its physical territories. Criticism of democracy should come from within culture. As I discuss in the book, "American philosophy allows us to go beyond the choice between American rootedness and cosmopolitanism" (Saito 2019, p. 98). Beginning with cultural criticism from within, we become cosmopolitan. And the thinkers I discuss in this book-Emerson, Thoreau, Dewey and Cavell-all begin with America, and explore the way to transcends its limits, 
criticizing the fallen state of America in their times. They are engaged in a process of "becoming cosmopolitan" (ibid.).

Those subtle but potentially significant differences between us make me wonder if what Arcilla interprets as translation in my book is slightly-possibly radically-different from what I intend it to be. And if so, I think the difference derives from our different takes on language and, more generally, our partly differing views of human nature. But Arcilla's sympathetic attention and constructive criticism of my book has brought me back to many points that I should further examine and clarify, and I am grateful that his thoughtful words have been addressed to the condition of my own words.

\section{References}

Arcilla, R. V. 2020. Making Sense of Ourselves with Others: Review of American Philosophy in Translation by Naoko Saito. Studies in Philosophy and Education (2020). https://doi.org/10.1007/s11217-02009737-6.

Cavell, S. 1979. The Claim of Reason: Wittgenstein, Skepticism, Morality and Tragedy. Oxford: Oxford University Press.

Cavell, S. 1989. This New Yet Unapproachable America: Lectures after Emerson after Wittgenstein. Albuquerque, New Mexico: Living Batch Press.

Cavell, S. 1992. The Senses of Walden. Chicago: The University of Chicago Press.

Saito, N. 2019. American Philosophy in Translation. London: Rowman \& Littlefield International, Inc.

Thoreau, H.D. 1992. Walden and Resistance to Civil Government. Ed. William Rossi. New York: W. W. Norton \& Company.

Wittgenstein, L. 1953. Philosophical Investigations, Trans. G.E.M. Anscombe. Oxford: Blackwell.

Publisher's Note Springer Nature remains neutral with regard to jurisdictional claims in published maps and institutional affiliations. 